\title{
Conversational Factors Discriminating between High- Functioning Autism Spectrum Disorders and Typical Development: Perceptual Rating Scale
}

\author{
Jieun Choi ${ }^{\mathrm{a}}$, YoonKyoung Lee ${ }^{\mathrm{b}}$ \\ ${ }^{a}$ Department of Speech-Language Pathology and Audiology, Graduate School of Hallym University, Chuncheon, Korea \\ ${ }^{b}$ Division of Speech Pathology and Audiology, Hallym University, Chuncheon, Korea
}

Correspondence: YoonKyoung Lee, $\mathrm{PhD}$ Division of Speech Pathology and Audiology, Hallym University, 1 Hallimdaehak-gil, Chuncheon 24252, Korea

Tel: $+82-33-248-2219$

Fax: +82-33-256-3420

E-mail: ylee@hallym.ac.kr

Received: April 20, 2019

Revised: May 23, 2019

Accepted: May 23, 2019

This article is an excerpt from the PhD's thesis of the first author (2019).

\begin{abstract}
Objectives: Children with autism spectrum disorder have difficulty with social interaction and communication. Social communication difficulties among these children are evident when conversing with other people. Conversational skills play an important role in the social aspects, such as the peer relationships, and academic achievement of school-aged children. The purpose of this study was to investigate the conversational characteristics of high-functioning autism spectrum disorder (HFASD) children in terms of linguistic, paralinguistic, and nonlinguistic factors and identify the conversational factors that distinguish the HFASD group. Methods: The participants were a total of 51 children: 17 HFASD children and 34 typical development (TD) children (17 matched on the chronological age and 17 matched on the language age). The 51 conversation samples were randomly numbered according to a set proportion between the two groups. A perceptual rating scale was performed by 6 speech-language pathologies to measure the linguistic, paralinguistic, and nonlinguistic characteristics. Results: The results were the following: among linguistic factors, the HFASD group had a significantly higher inappropriate initiation and frequency of overlap compared to that of the TD group. Regarding paralinguistic factors, the HFASD group scored significantly higher in changes of intensity, pitch, and intonation compared to the TD group. Finally, in regards to the nonlinguistic factors, the HFASD group scored significantly higher in posture, expression, inappropriate gesture, and eye-contact frequency and inappropriateness. The results of discriminant analysis indicated that the topic change frequency and topic maintenance frequency were found to be the most important discriminant factors. Conclusion: We discussed the factors of conversation which distinguish the HFASD group from TD group based on these results.
\end{abstract}

Keywords: Perceptual rating scale, High-functioning autism spectrum disorder, Linguistic, Nonlinguistic, Conversational factor
고기능 자폐스펙트럼장애 아동의 사회적 의사소통 및 상호작용 의 어려움은 자신의 의도를 전달하는 의사소통 수단의 적절한 사 용방법뿐만 아니라 상대방에게 의도를 이해시키는 데 필요한 것이 무엇인가를 고려하는 능력 모두에 영향을 미칠 수 있다(Wetherby, 1986). 따라서 이러한 사회적 의사소통의 어려움은 대화에서 두드 러지게 나타나게 된다. 자폐스펙트럼장애 아동의 사회적 의사소통 결함은 다른 사람과의 대화를 어렵게 하며, 이는 또래와 적절한 사
회적 관계를 형성하는 데 어려움을 줄 수 있고, 의사소통 상황에서 또래로부터 소외당하거나 사회적 문제들을 야기시킬 수 있다. 따라 서 고기능 자폐스펙트럼장애 아동의 대화 능력을 살펴보는 것은 매우 중요하다.

대화는 일상생활 안에서 자연스럽게 사회적인 언어로서 사용되 는 것으로 두 사람 이상이 서로 이야기를 주고받는 양방향 의사소 통이다(Choi \& Lee, 2013, 2015; Heo \& Lee, 2012; Nippold, Hes- 
keth, Duthie, \& Mansfield, 2005). 사람들과 정보를 얻거나 나누기 위해, 생각을 표현하고 중요한 관계를 형성하고 유지하기 위한 대화 는 주로 언어를 통해 이루어진다. 하지만, 언어 표현만으로 의사 전 달이 충분히 되지 않는 경우에는 언어 외적인 부분도 함께 사용하 여 의사소통하는 것이 매우 중요하다(Knapp \& Hall, 2009). 언어 외적인 부분에는 준언어적, 비언어적 요인이 고려될 수 있다. 언어에 부수되어 표현되는 준언어적 요인에는 목소리 높낮이, 크기, 말속 도, 강도 등이 있으며, 언어 이외의 수단으로 의도를 표현하는 비언 어적 요인에는 몸짓, 눈맞춤, 자세 등이 포함된다. 대화에서는 언어 적인 것뿐만 아니라 준언어, 비언어적 요인도 영향을 미치는데, 한 연구에 의하면 대화 시 의도를 표현할 때 언어가 차지하는 비중은 $7 \%$, 준언어는 $38 \%$, 비언어적 의사소통은 $55 \%$ 를 차지한다고 보고 하기도 하였다(Mehrabian, 1981). 즉 대화에서는 언어뿐만 아니라 준언어, 비언어적 요인이 함께 영향을 미칠 수 있다. 따라서 대화에 서는 언어적인 것뿐만 아니라 준언어, 비언어적인 요인을 함께 살펴 보는 것이 중요하다.

자폐스펙트럼장애 아동의 대화 특성을 살펴보기 위한 대부분의 연구는 자연스러운 환경이나 구조화된 환경에서 실제 대화 샘플을 수집하고 목표 행동을 관찰, 분석하는 행동 분석방법을 통해 진행 되어 왔다. 행동 분석을 통해 대화 특성을 살펴본 선행연구들은 주 로 대화차례 주고받기와주제관리능력을 중심으로 분석하였다. 대 화차례 주고받기의 경우 대화 상대방과 대화차례를 얼마나 많이 주고받는지 확인하기 위해 대부분 대화차례 주고받기 빈도를 분석 하였으며(Choi \& Lee, 2013, 2015; Curcio \& Paccia, 1987; Jo, 2002; Tager-Flusberg \& Anderson, 1991 등), 대화 시 대화 주제를 어떻게 다루는지 확인하기 위해 전체 대화차례 중에서 주제유지나 주제변 경이 차지하는 비율 또는 빈도를 측정하여 살펴보았다(Choi \& Lee, 2013, 2015; Nadig, Lee, Singh, Bosshart, \& Ozonoff, 2010; TagerFlusberg \& Anderson, 1991; Yang \& Choi, 2010 등). 하지만 이러한 방법은 신뢰도가 높은 자료 수집과 분석을 위해 많은 시간과 노력 이 필요하며 비언어적, 준언어적 행동을 측정하는 데 어려움이 있 을 수 있다(Brinton, Fujiki, \& Powell, 1997; Mentis, 1994).

이러한 어려움을 보완하기 위한 방법으로 연구자들은 평정 척도 를 활용하여 자폐스펙트럼장애 아동의 대화 특성을 살펴보았다. Seo (2013)는 고기능 자폐장애 청소년 10명, 아스퍼거장애 청소년 3 명을 대상으로 비언어적 의사소통 행동에 관한 화용론적 평정 척 도를 활용하였는데, 그 결과 고기능 자폐장애 청소년은 준언어적 행동 중 음성 크기, 반응 타이밍, 속도, 리듬, 발음 억양 순으로 문제 정도가 심하며, 비언어적 행동에서는 부적절한 시선, 얼굴 표정, 몸 짓/손짓, 신체적 거리 순으로 문제 정도가 심하다고 보고하였다. 또
한 Bauminger-Zviely, Karin, Kimhi와 Agam-Ben-Artzi (2014)는 또래와의 자유놀이를 관찰하여 PRS (Landa et al., 1992)로 평가하 였을 때, 고기능 자폐스펙트럼장애 아동은 언어적 측면의 항목인 '관련성 없는 정보 제공, 상호적인 대화 적음, 부적절한 주제변경, 부 적절한 주제 등'과 준언어적 측면의 항목인 '너무 빠르거나 느린 말 속도, 비정상적인 억양 등', 비언어적 측면의 항목인 '부적절한 몸짓, 물리적 거리, 얼굴 표정, 눈 응시'에서 일반아동과 유의한 차이를 보 인다고 보고하였다.

이처럼, 자폐스펙트럼장애 아동의 언어적, 비언어적 대화 요인을 살펴보기 위해 평정 척도를 활용하여 연구가 진행되었다. 하지만 선행연구들은 각 요인별 대화 행동 특성만을 보고하여 각각의 요 인 중 대화에 가장 영향을 미치며 자폐스펙트럼장애 아동을 확인 해 줄 수 있는 요인이 무엇인지 확인하기에는 어려움이 있다. 따라 서 본 연구에서는 지각적 평가를 사용하여 전문가가 인식하는 고 기능 자폐스펙트럼장애 아동의 대화 특성을 살펴보고, 집단 간 차 이를 보인 대화 요인 중 자폐스펙트럼장애 집단과 일반아동 집단을 판별해 줄수 있는 요인이 무엇인지 확인하고자 하였다.

\section{연구방법}

\section{연구 대상}

대화 자료 수집

본 연구의 대상은 강원 및 경기지역 초등학교에 재학 중인 고기 능 자폐스펙트럼장애(high-functioning autism spectrum disorder, HFASD) 아동 17 명, 일반아동 34 명(언어연령일치 일반아동 17 명, 생활연령일치 일반아동 17 명)으로 총 51 명이다. 본 연구에서는 대 화 능력이 언어 능력과 더불어 아동의 생활경험 능력에도 영향을 받기 때문에(Hoff, 2009), 언어연령을 일치시킨 일반아동뿐만 아니 라 생활연령을 일치시킨 일반아동을 함께 포함하였다.

고기능 자폐스펙트럼장애 아동은 (1) 대학병원이나 종합병원 소 아정신과 전문의에 의해 자폐스펙트럼장애로 진단받거나 의심된 다고 보고된 아동 중, (2) Autism Diagnostic Observation Schedule-Second Edition (ADOS-2; Lord et al., 2012) module 3 결과, 전 체 알고리즘 점수가 7점 이상으로 자폐스펙트럼에 해당하고, 사회 적 의사소통 설문지(Social Communication Questionnaire, SCQ; Yoo, 2008) 검사 결과 자폐스펙트럼장애 기준에 해당하는 15 점 이 상이며, (3) 한국 비언어지능검사-2 (Korean version of Comprehensive Test of Nonverbal Intelligence second edition, K-CTONI-2; Park, 2014)의 지능지수가 80 이상이고, (4) 수용-표현어휘력 검사(Receptive \& Expressive Vocabulary Test, REVT; Kim, Hong, 
Kim, Jang, \& Lee, 2009) 결과가 10 백분위수 이상, 학령기 아동언어 검사(Language Scale for School-aged Children, LSSC; Lee, Heo, \& Jang, 2015) 중 수용언어 및 표현언어 능력과 높은 상관을 보인 '단 락듣기 이해', ‘문법 판단 및 수정' 문항검사 결과 환산점수 10 점 내 외(-1 SD 이상)에 해당하며, (5) 상대방과의 대화에서 신체적 장애 (시각-청각장애, 신체적 결함, 심한 행동장애)로 인해 방해받지 않 는 아동으로 선정하였다.

일반아동은 (1) 부모와 주양육자, 교사에 의해 발달이 정상적으 로 이루어졌다고 보고된 아동들로, (2) 고기능 자폐스펙트럼장애 아동과 일대일로 일치시켰을 때 같은 학년에 속하는 아동 1 명과 REVT 표현언어 원점수가 같은 연령대에 해당하는 1 명 각 2 명씩 매 치하였고, (3) 시각 및 감각장애나 심각한 정서 문제를 보이지 않는 아동으로 선정하였다.

모든 아동의 부모님들에게 검사 실시 전 부모동의서를 얻은 후, 모든 절차를 진행하였다. 고기능 자폐스펙트럼장애 아동 집단과 일반아동 집단은 REVT 표현어휘연령, LSSC 하위 문항별 환산점 수, K-CTONI-2 지능지수에서 유의한 차이가 없었고, SCQ에서만 유의한 차이가 있었다. 연구대상의 기본 정보는 Table 1 과 같다.

Table 1. Participants' information

\begin{tabular}{lccc}
\hline Group & $\begin{array}{c}\text { HFASD group } \\
(\mathrm{N}=17)\end{array}$ & $\begin{array}{c}\text { TD group } \\
(\mathrm{N}=34)\end{array}$ & $t$ \\
\hline Chronological age $(\mathrm{mo})$ & $98.83 \pm 18.59$ & $99.31 \pm 20.70$ & \\
Autism diagnostic test & & & \\
$\quad$ SCO & $18.28 \pm 4.47(15-31)$ & $1.63 \pm 1.90(0-7)$ & $18.437^{* * *}$ \\
ADOS-2 total score & $11.94 \pm 3.56(8-20)$ & - & - \\
Language test & & & \\
REVT-E language age & $88.72 \pm 22.16$ & $92.25 \pm 23.38$ & -.522 \\
LSSC USP standard score & $8.57 \pm 2.70$ & $11.07 \pm 3.27$ & -1.742 \\
LSSC GEJ standard score & $8.86 \pm 1.68$ & $10.43 \pm 1.70$ & -2.008 \\
LSSC GER standard score & $8.71 \pm 1.25$ & $10.71 \pm 2.46$ & -2.004 \\
Intelligence test & & & \\
K-CTONI-2 & $99.56 \pm 9.96$ & $99.28 \pm 13.62$ & .075 \\
K-WISC-III or -IV & $96.23 \pm 14.62$ & - & - \\
\hline
\end{tabular}

Values are presented as mean \pm SD (range).

HFASD = high functioning autism spectrum disorders; TD = typical development; SCQ = Social Communication Questionnaire (Yoo, 2008); ADOS-2 = Autism Diagnostic Observation Schedule-second edition (Lord et al., 2012); REVT= Receptive and Expressive Vocabulary Test (Kim, Hong, Kim, Jang, \& Lee, 2009); LSSC=Language Scale for School-aged Children (Lee, Heo, \& Jang, 2014); USP= understanding spoken paragraph; GEJ=grammatical error judgement; GER=grammatical error revision; K-CTONI-2 = Korean version of Comprehensive Test of Nonverbal Intelligence second edition (Park, 2014); K-WISC=Korean Wechsler Intelligence Scale for Children.

${ }^{* * *} p<.001$.

\section{지각적 평가}

지각적 평가를 통해 고기능 자폐스펙트럼장애 아동과 일반아동 의 대화 특성을 확인하기 위하여 고기능 자폐스펙트럼장애 아동 교육 또는 치료 경험이 최소 3 년인 언어재활사 6명을 평가자로 선정 하였다. 대화 지각적 평가에 참여한 평가자의 정보는 Table 2에 제 시하였다. 전체 평가자의 임상경력은 최소 3 년에서 최대 18 년까지 평균 8 년이었다. 평가자 6 명 중 1 명의 경력이 3 년이나 본 평가자는 자폐스펙트럼장애 아동들을 주로 보는 임상현장에서 일을 하고 있 었다. 평가자 6명 중 5명은 모두 대화 자료 수집 및 분석에 참가한 경험이 있었다.

\section{자료 수집 도구 \\ 대화자료 샘플}

학령기 고기능 자폐스펙트럼장애 아동의 언어적, 비언어적 대화 특성을 평가하기 위해 먼저 연구자와 일대일로 조용한 방에서 한 림 대화·화용평가 프로토콜(Lee \& Choi, in press) 중 대화 절차를 사용하여 대화 자료를 수집하였다. 대화유도 절차는 Evans와 Craig (1992) 그리고 Brinton 등(1997)의 연구에 기초하여 개발되었으며, Heo와 Lee (2012), Choi와 Lee (2013, 2015), Hong과 Lee (2016)의 연구를 통해 절차가수정 및 보완되었다.

대화 주제는 아동에게 익숙한 '가정생활, 학교생활, 기타/친구'로 선정하였으며, 대화 시 대상자의 자발적인 주제 개시를 살펴보기 위해 '가정생활', '학교생활'과 관련된 사진을 각각 4 개씩 준비하여 봉투 안에 담아두었고, '기타/친구'는 사진 자료 없이 구어로 주제 를 제시하였다. 각각의 주제별로 3 가지의 소주제 질문을 사전에 준 비하였으며, 소주제는 '가정생활'에 주말, 명절, 생일, '학교생활'에 는 점심/쉬는 시간, 방과후, 현장학습, '기타/친구'에는 놀이, 좋아하 는 것, TV프로그램이었다. 모든 아동에게 연구자는 대화 상대자 요 인을 최소화하되 자연스러운 대화를 유지하기 위해 아동의 대화차 례가 끝나면 새로운 질문이나 내용을 첨가하지 않고 아동의 이전 발화의 말을 반복해 주며 중립적인 반응을 해주었다. 2-3초 이후에 도 발화를 이어나가지 않는 경우 “그리고?”, “또?”와 같이 촉진해

Table 2. Rater's information

\begin{tabular}{lccc}
\hline & Age (yr) & Clinical experience (yr) & Level of education \\
\hline Rater 1 & 46 & 18 & $\mathrm{PhD}$ \\
Rater 2 & 34 & 11 & $\mathrm{PhD}$ \\
Rater 3 & 31 & 6 & $\mathrm{MS}$ \\
Rater 4 & 31 & 6 & $\mathrm{MS}$ \\
Rater 5 & 27 & 5 & $\mathrm{MS}$ \\
Rater 6 & 27 & 3 & MS \\
\hline
\end{tabular}


주며 대화를 이어나가도록 하였다. 각 주제에서 아동이 끝맺는 말, 할 말이 없다는 행동(시선, 미소, 무반응 등)을 보이면 다음 주제를 선택하게 한 후, 앞의 절차로 대화를 진행하였다.

대화를 진행하기 전 각 아동의 부모님에게 녹음 및 녹화에 대한 사전 동의를 받은 후 아동의 대화를 진행하였다. 모든 대화는 아동 이 치료를 받고 있는 치료실이나 아동 집의 독립된 장소에서 Tantam, Holmes와 Cordess (1993)의 연구를 참고하여 디지털 캠코더 2대와 녹음기를 이용하여 녹음 및 녹화하였다(Figure 1). 아동과의 대화는 아동의 옷에 걸 수 있는 선걸이형 마이크와 디지털 보이스 레코더를 사용하여 녹음하였으며, 녹음 시 마이크는 아동의 입에 서 약 $15 \mathrm{~cm}$ 정도 떨어진 곳에 위치하도록 하고 핀을 이용하여 옷 에 고정시킨 후(Van Santen, Prud'hommeaux, Black, \& Mitchell, 2010).

51 명의 대화 자료는 집단이 무작위로 섞이도록 한 후 1 번부터 51 번까지 번호를 부여하였다. 이때 무작위로 부여된 번호가 한 집단 에 쏠리는 것을 방지하기 위해 집단 간 비율을 조절하여 번호를 부 여하였다. 2 개의 캠코더로 녹화된 총 51 명의 대화 자료 동영상은 '곰 앤컴퍼니'사의 동영상 캠퍼/녹화 프로그램인 곰캠을 활용하여 두 영상이 동시에 재생되도록 편집하였다. 동영상은 검사자가 아동에 게 대화 절차에 대해 설명하는 도입 부분을 제외하고 2 개 영상의 시간 축을 확인하여 동일한 시간으로 재생되도록 편집하였다(Figure 2).

\section{대화 지각적 평정 척도}

대화 지각적 평정 척도는 자폐스펙트럼장애 아동의 대화 특성을 살펴보기 위해작성되었다. 대화 지각적 평정 척도를 작성하기 위해 대화 관련 문헌과 자폐스펙트럼장애 아동의 대화 선행문헌, 자폐스 펙트럼장애 아동의 대화 척도—예: PRS (Landa et al., 1992), CCC2 (Bishop, 2003), TOPICC (Adams et al., 2012), Pragmatic Proto- col (Prutting \& Kittchner, 1987)—와 대화 특성을 살펴본 선행연 구들(Choi \& Lee, 2013, 2015; Heo \& Lee, 2012; Hong \& Lee, 2016; Park, Choi, \& Lee, 2017; Yang, Lee, Choi, \& Yoon, 2018)에서 다뤄 진 변수 등을 종합하여 분석하였다.

평정 척도 질문은 자폐스펙트럼장애에게 보고되는 비정상적인 행동들을 반영한 항목으로 구성하였으며, 크게 대화의 언어적 요 인(대화 기술), 준언어적 요인, 비언어적 요인의 3가지 영역으로 분 류하였다. 일부 항목(대화 시작, 주제유지, 주제변경, 목소리 크기 변화, 억양, 표정, 몸짓, 시선)의 경우 적절성에 대한 항목도 함께 추 가적으로 질문하여 특정 대화 행동의 적절성 여부에 대한 지각적 인 부분도 확인하였다. 예를 들어 대화의 준언어적 요인 중 억양의 경우, 자연스러우면 0 점, 약간 부자연스러우면 1점, 매우 부자연스 러우면 2점, 매우 심하게 부자연스러운 경우 3점으로 평가하도록 구성하였다. 설문지 구성 및 문항은 Table 3과 같다.

작성된 지각적 평정 척도는 1 차적으로 대화를 주로 연구한 언어 병리학 박사 1 인에게 대화 능력을 평가하는 기준인 항목들과 각 항 목에 따른 4 점 척도가 적절한지에 대한 내용적인 면과 형식적인 면 에 대해 의견을 물은 후, 수정 및 보완하였다. 수정된 평정 척도는 2 차적으로 언어병리학전공 박사 2 인에게 내용타당도를 검증하였다. 대화 능력을 평가하기 위한 각각의 항목들이 적절한지에 대한 내용 타당도의 평가는 5 점 척도 $(1$ 점=전혀 타당하지 않다, 2 점=타당하 지 않다, 3점 $=$ 보통이다, 4 점 $=$ 타당하다, 5 점 $=$ 매우 타당하다)를 사용하였다. 각 항목에 대한 내용타당도 점수는 평균 4.3 점으로 높 은 내용 타당도 점수를 보였다.

문항의 척도는 4 점 평정척도로 구성되었다. 각 문항은 최하 0 점 에서 최고 3점이며, 각 항목별 점수를 산출하였다. 점수 기준은 항 목마다 다르지만 0 점이 기준점으로 점수가 높아질수록 특정 대화 행동에서 적절하지 못하다는 것을 의미하였다.

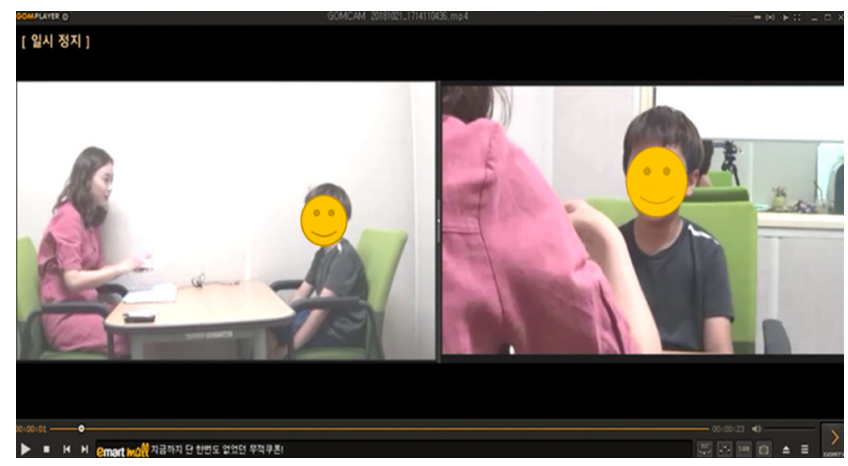

Figure 2. Examples of conversation data editing.

Figure 1. Placing of camcorders and tripods. 
Table 3. Domain and contents of the perceptual rating scale

\begin{tabular}{lcc}
\hline Domain & \multicolumn{1}{c}{ Contents } & $\begin{array}{c}\text { No. of } \\
\text { item }\end{array}$ \\
\hline $\begin{array}{c}\text { Linguistic factor (conver- } \\
\text { sational skills) }\end{array}$ & Turn-taking, topic manipulation, etc. & 8 \\
Paralinguistic factor & $\begin{array}{c}\text { Speech rate, voice loudness, voice loudness } \\
\text { variation, voice pitch, prosody, etc. }\end{array}$ & 5 \\
Nonlinguistic factor & $\begin{array}{c}\text { Gesture, posture, facial expression, eye } \\
\text { contact (gaze), etc. }\end{array}$ & 6 \\
\hline
\end{tabular}

\section{자료 전사 및 자료 분석}

참여 의사를 밝힌 전문가들에게 연구목적과 절차 및 검사 내용 을 먼저 설명하고 연구 참여동의서에 동의한다는 서명을 받았다. 또한 평가에 사용되는 녹화된 영상 자료의 비밀 유지에 대한 서명 을 받은 후 평가를 진행하였다. 지각적 평가에 참여하는 평가자들 에게 평정 지침을 숙지하도록 평정 척도에 대한 설명과 교육을 실시 하였다. 평가자별로 평정 지침에 대해 숙지가 되었다고 판단되면, 무작위로 부여된 대화 자료를 보고 개별적으로 평가하도록 하였다. 1 개의 대화 자료는 10 분 내외로, 1 개의 대화 자료 영상을 본 후 약 1 분간 해당 아동의 평가 척도를 완성하도록 하였다.

전체 51 개의 자료 중 4 개의 자료는 모든 전문가가 공통적으로 분 석하도록 하였다. 4 개의 자료를 제외한 대화 샘플 자료는 2 명의 전 문가가 평가하여 개인차를 줄이도록 하였으며(Yoon, Lee, \& Sim, 2000), 1 명의 전문가에게 모든 대화 샘플을 제시하여 평가하게 하 였을 때 학습효과가 발생할 가능성을 사전에 예방하기 위해(Osberger, 1992), 6 명의 전문가들은 각각 17-18개의 대화 자료를 평가 하도록 하였다(Table 4).

\section{자료 분석}

각 대화자료에 해당하는 지각적 평가 결과는 대화의 언어적 요인, 준언어적 요인, 비언어적 요인 각각의 항목별 점수를 산출하였다. 언 어적 요인의 경우 최소 0 점-최대 24 점, 준언어적 요인은 최소 0 점-최 대 15 점, 비언어적 요인은 최소 0 점-최대 18 점을 받을 수 있었다.

\section{신뢰도}

6명의 평가자가 공통적으로 평정한 4 개 대화 자료에 대한 지각적 평정 척도 결과의 평가자 간 신뢰도는 각 대화 요소별 급내상관계 수(intraclass correlation coefficients, ICC)로 측정하였다. 신뢰도 측정 결과 크게 대화의 언어적 요인은 .975 , 준언어적 요인은 .948, 비언어적 요인은 .988로 매우 높게 나타났다. 문항별로 살펴보았을 때, 언어적 요인의 대화시작 빈도(.632)를 제외한 모든 항목은 .80.97로 나타났고, 준언어적 요인에서는 목소리 크기(.525)를 제외한
Table 4. Conversational material

\begin{tabular}{lclc}
\hline & $\begin{array}{c}\text { Reliability evalua- } \\
\text { tion (common) }\end{array}$ & $\begin{array}{c}\text { Individual } \\
\text { evaluation }\end{array}$ & Total number \\
\hline Rater 1 & $\# 1-4$ & $\# 5-11, \# 12-18$ & 18 \\
Rater 2 & $\# 1-4$ & $\# 12-18, \# 19-25$ & 18 \\
Rater 3 & $\# 1-4$ & $\# 19-25, \# 26-32$ & 18 \\
Rater 4 & $\# 1-4$ & $\# 26-32, \# 33-39$ & 18 \\
Rater 5 & $\# 1-4$ & $\# 39-45, \# 46-51$ & 17 \\
Rater 6 & $\# 1-4$ & $\# 46-51, \# 5-11$ & 17 \\
Total number & $\# 1-4$ & 47 & 51 \\
\hline
\end{tabular}

모든 항목이 .84-.95로 나타났다. 마지막으로 비언어적 요인의 신뢰 도는 모든 항목에서 .83-98 사이에 해당하였다. Nunnally (1978)는 Cronbach 알파값이 .60 이상이면 신뢰할 수 있다고 하였는데, 대부 분 .80-.90에 속하여 높은 신뢰도를 보인다고 해석할 수 있다.

\section{통계 처리}

지각적 평정 척도를 통한 고기능 자폐스펙트럼장애 집단의 대화 특성이 일반아동 집단 간 차이가 있는지 확인하기 위해 독립표본 $t$-검정을 실시하였다. 또한 고기능 자폐스펙트럼장애 아동과 일반 아동 집단을 판별할 수 있는 언어적, 준언어적, 비언어적 대화 요인 을 확인하기 위해 대화 요인을 독립변인으로 하고 집단을 종속변인 으로 한 단계적 판별분석(stepwise discriminant analysis)을 실시 하였다. 통계분석에 사용한 프로그램은 SPSS version 25 였다.

\section{연구결과}

\section{고기능 자폐스펙트럼장애 아동 집단과 일반아동 집단 간 대화 특성 차이 대화의 언어적 요인}

고기능 자폐스펙트럼장애 집단과 일반아동 집단의 대화의 언어 적 요인에서 어떠한 차이를 보이는지 살펴본 결과(Table 5), 대화개 시 빈도 $(t=-0.868, p=.390)$ 와 대화중단 $(t=1.755, p=0.086)$ 에서는 집단간 유의한차이를 보이지 않았으나, 대화개시의 적절성 $(t=5.444$, $p<.001)$, 대화중첩 $(t=2.505, p<.05)$, 주제유지 빈도 $(t=6.521, p<$ $.001)$, 주제유지 적절성 $(t=5.684, p<.001)$, 주제변경 빈도 $(t=5.758$, $p<.001)$, 주제변경 적절성 $(t=5.931, p<.001)$ 에서는 집단 간 유의 한차이가 나타났다.

즉 전문가들은 고기능 자폐스펙트럼장애 집단이 일반아동 집단 보다 대화 시작이 부적절하며, 끼어들기를 자주하는 것으로 지각 하였다. 또한 자폐스펙트럼장애 집단은 일반아동 집단에 비해 주제 
유지를 하지 못하는 반면 주제 변경하는 빈도는 많다고 평가되었 고, 주제유지와주제변경을 하더라도 부적절하다고 지각되었다.

\section{대화의 준언어적 요인}

고기능 자폐스펙트럼장애 집단과 일반아동 집단의 대화의 준언 어적 요인에서 어떠한 차이를 보이는지 살펴본 결과(Table 6), 말속 도 $(t=.0761, p=.451)$, 목소리 크기 $(t=1.225, p=.227)$ 에서는 두 집 단 간 유의한 차이를 보이지 않았으나, 목소리 크기 변화 $(t=3.242$, $p<.01)$, 목소리 높낮이 $(t=4.277, p<.001)$, 억양 $(t=5.010, p<.001)$ 에서는 두 집단 간 유의한 차이가 나타났다.

즉, 전문가들은 고기능 자폐스펙트럼장애 집단이 일반아동 집 단에 비해 목소리 크기 변화가 부적절하며, 목소리 높낮이가 더 높 거나 낮고 억양이 부적절하다고 지각하였다.

\section{대화의 비언어적 요인}

대화의 비언어적 요인에서 집단 간 어떠한 차이를 보이는지 살펴

Table 5. Comparison of linguistic between HFASD and TD groups

\begin{tabular}{lccc}
\hline & $\begin{array}{c}\text { HFASD group } \\
(\mathrm{N}=17)\end{array}$ & $\begin{array}{c}\text { TD group } \\
(\mathrm{N}=34)\end{array}$ & $t$ \\
\hline $\begin{array}{l}\text { Initiation of conversation } \\
\text { Frequency }\end{array}$ & $0.33 \pm 0.84$ & $0.53 \pm 0.73$ & -.868 \\
$\quad$ Appropriacy & $1.33 \pm 0.91$ & $0.27 \pm 0.45$ & $5.444^{* * *}$ \\
Breakdown of conversation & $0.89 \pm 0.76$ & $0.53 \pm 0.63$ & 1.755 \\
Overlap of conversation & $0.67 \pm 1.08$ & $0.13 \pm 0.35$ & $2.505^{*}$ \\
Maintenance of topic & & & \\
$\quad \begin{array}{l}\text { Frequency } \\
\text { Appropriacy }\end{array}$ & $1.72 \pm 1.13$ & $0.23 \pm 0.43$ & $6.521^{* * *}$ \\
Change of topic & $1.50 \pm 1.04$ & $0.27 \pm 0.45$ & $5.684^{* * *}$ \\
$\quad$ Frequency & & & \\
Appropriacy & $1.61 \pm 1.20$ & $0.20 \pm 0.48$ & $5.758^{* * *}$ \\
\hline
\end{tabular}

Values are presented as mean $\pm S D$.

HFASD= high functioning autism spectrum disorders; $T D=$ typical development. ${ }^{*} p<.05,{ }^{* * *} p<.001$.

Table 6. Comparison of paralinguistic between HFASD and TD groups

\begin{tabular}{lccc}
\hline & $\begin{array}{c}\text { HFASD group } \\
(\mathrm{N}=17)\end{array}$ & $\begin{array}{c}\text { TD group } \\
(\mathrm{N}=34)\end{array}$ & $t$ \\
\hline Speech rate & $0.56 \pm 0.92$ & $0.40 \pm 0.50$ & .761 \\
Voice loudness & $0.78 \pm 0.88$ & $0.50 \pm 0.68$ & 1.225 \\
Voice loudness variation & $0.72 \pm 0.83$ & $0.13 \pm 0.43$ & $3.242^{* *}$ \\
Voice pitch & $0.94 \pm 0.87$ & $0.17 \pm 0.38$ & $4.277^{* * *}$ \\
Prosody & $1.00 \pm 0.91$ & $0.10 \pm 0.31$ & $5.010^{* * *}$
\end{tabular}

Values are presented as mean \pm SD.

HFASD = high functioning autism spectrum disorders; $T D=$ typical development. ${ }^{* * *} p<.01,{ }^{* * *} p<.001$.
본 결과(Table 7), 몸짓 빈도 $(t=0.868, p=.390)$ 를 제외한 모든 요인인 자세 $(t=4.377, p<.001)$, 표정 $(t=3.951, p<.001)$, 몸짓 적절성 $(t=4.604$, $p<.001)$, 눈맞춤 빈도 $(t=5.399, p<.001)$, 눈맞춤 적절성 $(t=5.883$, $p<.001)$ 에서 두 집단 간 유의한차이가 나타났다.

즉, 전문가 집단은 고기능 자폐스펙트럼장애 집단이 일반아동에 비해 자세와 표정이 부적절하며, 산만하다고 평가하였고, 몸짓 사 용에서도 부적절하며, 눈맞춤 빈도가 적고, 눈맞춤을 하더라도 부 적절하다고 지각하였다.

\section{대화에서의 고기능 자폐스펙트럼장애 아동 집단과 일반아동 집단 판별분석}

집단 간 유의한 차이를 보인 14 가지 요인(대화시작 적절성, 대화 중첩, 주제유지 빈도, 주제유지 적절성, 주제변경 빈도, 주제변경 적 절성, 목소리 크기 변화, 목소리 높낮이, 억양, 눈맞춤 빈도, 눈맞춤 적절성, 자세, 표정, 몸짓 적절성)을 독립변수로 하고, 집단을 종속 변수로 한 단계적 판별분석을 실시한 결과, 도출된 함수는 두 집단 을 판별하기에 유의하였다(eigenvalue $=1.204$, 정준상관계수 $=.739$, Wilks' $\lambda=.454, \chi=35.566, p<.001)$.

구조행렬(structure matrix)을 통해 집단의 판별에 대한 대화 요 인의 상대적 중요도를 살펴본 결과는 Table 8에 제시하였다. 각 사 례의 판별점수와 그 사례가 갖는 예측변인에 대한 값의 상관을 구 한 중요도는 값이 클수록 변인들 사이에서 판별의 기여도가 높은 것으로 해석할 수 있다. 본 연구결과에서는 주제변경 빈도, 주제유 지 빈도 순으로 높은 중요도를 보였다.

본 연구에서 분류한 집단이 얼마나 정확하게 분류되었는지 살펴 본 결과, 총 51 명 중 39 명이 정확히 분류되어 $82.4 \%$ 의 정확도를 보 였다. 집단별로 살펴보면, 고기능 자폐스펙트럼장애 집단에서는 총 17 명 중 13 명을 정확하게 분류하여 $76.4 \%$ 의 민감도(Sensitivity)를

Table 7. Comparison of nonlinguistic between HFASD and TD groups

\begin{tabular}{lccc}
\hline & $\begin{array}{c}\text { HFASD group } \\
(\mathrm{N}=17)\end{array}$ & $\begin{array}{c}\text { TD group } \\
(\mathrm{N}=34)\end{array}$ & $t$ \\
\hline Eye contact & & \\
Frequency & $1.33 \pm 1.03$ & $0.20 \pm 0.41$ & $5.399^{* * *}$ \\
Appropriacy & $1.17 \pm 0.86$ & $0.13 \pm 0.35$ & $5.883^{* * *}$ \\
Posture & $0.94 \pm 1.06$ & $0.07 \pm 0.25$ & $4.377^{* * *}$ \\
Facial expression & $0.83 \pm 0.71$ & $0.20 \pm 0.41$ & $3.951^{* * *}$ \\
Gesture & & & \\
Frequency & $0.83 \pm 0.86$ & $0.63 \pm 0.72$ & .868 \\
Appropriacy & $0.94 \pm 1.00$ & $0.07 \pm 0.25$ & $4.604^{* * *}$ \\
\hline
\end{tabular}

Values are presented as mean \pm SD.

HFASD = high functioning autism spectrum disorders; $T D=$ typical development ${ }^{* * *} p<.001$. 
Table 8. Relative importance of conversational factors

\begin{tabular}{lc}
\hline Discriminative variables & Structure matrix \\
\hline Frequency of topic change & .882 \\
Frequency of topic maintenance & .876 \\
\hline
\end{tabular}

나타냈으며, 일반아동 집단에서는 34 명 중 29 명을 정확하게 분류 하여 $85.3 \%$ 의 특이도(Specificity)를 나타냈다.

\section{논의 및 결론}

본 연구는 지각적 평가를 통해 고기능 자폐스펙트럼장애 아동의 대화 특성을 언어적, 준언어적, 비언어적 요인으로 나누어 일반아 동 집단과 어떠한 차이가 있는지 살펴보고, 각 대화 요인 중 고기능 자폐스펙트럼장애 아동을 판별해 줄 수 있는 요인이 무엇인지 밝히 고자하였다.

먼저 대화의 언어적 측면 중 대화차례 주고받기의 경우, 대화개 시의 빈도와 대화중단에서는 집단 간 차이가 없었으나, 대화개시의 적절성, 대화중첩(끼어들기)에서는 집단 간 유의한 차이가 나타났 다. 즉 전문가 집단은 고기능 자폐스펙트럼장애 아동이 대화를 시 작하는 상황에서 대화를 시작할 수 있으나 대화를 시작하는 것이 부적절하다고 지각하였으며, 상대방의 대화차례가 끝나지 않았음 에도 불구하고 끼어드는 빈도가 많은 것으로 지각하였다. 실제로 대화에서 대화개시가 차지하는 비율은 $2 \%-3 \%$ 로 매우 낮다고 볼 수 있다(Choi \& Lee, 2013; Heo \& Lee, 2012; Hong \& Lee, 2016). 다 른 사람에게 있어 고기능 자폐스펙트럼장애 아동이 얼마나 많이 대화를 시작하는지보다는 대화개시를 어떠한 방법으로 적절하게 하는지에 대해 더 중점을 두고 집단을 다르게 지각한다고 볼 수 있 다. 또한 전문가 집단은 고기능 자폐스펙트럼장애 아동이 대화중 첩 빈도가 많은 것으로 지각하였다. Choi와 Lee (2013)는 학령기 고 기능 자폐스펙트럼장애 아동의 대화 특성을 행동분석을 통해 살 펴보았을 때, 일반아동에 비해 상대방의 대화차례가 끝나지 않았 음에도 불구하고 끼어드는 빈도가 많다고 보고하였다. 즉 행동분 석에서 고기능 자폐스펙트럼장애 아동이 대화차례에 끼어드는 행 동 빈도가 많은 특징은 전문가 집단에게서도 유의미하게 다르다고 지각될 수 있다고 볼수 있다.

주제관리능력의 경우, 주제유지 빈도와 적절성, 주제변경 빈도와 적절성 모두에서 유의한 차이가 나타났다. 즉 전문가 집단은 고기 능 자폐스펙트럼장애 아동이 일반아동에 비해 대화 주제를 유지 하는 빈도는 적은 반면, 주제를 변경하는 빈도가 많다고 평가하였 고, 주제를 유지하고 변경하는 것 모두 일반아동에 비해 부적절하
다고 지각하였다. 본 연구에서 참여한 고기능 자폐스펙트럼장애 아동은 특정 주제로 대화를 유지해 가는 경우 필요하지 않은 정보 를 매우 상세하게 이야기를 하는 것이 많았으며, 현재 이야기하고 있는 내용을 마무리하지 않고 갑자기 다른 이야기를 하는 등 부적 절한 모습이 관찰되었다. 이러한 결과는 지각적 평가를 통해 살펴 본 선행연구에서도 보고되었는데, Paul, Orlovski, Marcinko와 Volkmar (2009)는 지각적 평가를 통해 16-22세의 고기능 자폐스펙 트럼장애 집단과 생활연령을 일치시킨 일반집단을 대상으로 대화 능력을 평가하여 고기능 자폐스펙트럼장애 집단이 부적절하게 형 식적이거나 상세한 주제로 대화를 이어나가거나 주제에서 벗어나 는 경우가 많다고 보고하였다. 또한 지각적 평가를 통해 주제관리 능력을 살펴본 다른 선행연구들에서도 고기능 자폐스펙트럼장애 아동은 일반아동에 비해 관련성이 없거나 부적절한 세부 정보를 제공하고, 부적절한 주제로 대화를 이어나가며(Bauminger-Zviely et al., 2014; Lam \& Yeung, 2012), 갑작스럽게 주제를 변경하거나주 제에서 벗어나는 내용으로 이야기를 한다고 지각되었다(Lam \& Yeung, 2012). 즉 고기능 자폐스펙트럼장애 아동은 대화 상대방의 집중이나 흥미, 정서를 고려하지 못하여(Tager-Flusberg, Paul, \& Lord, 2005) 너무 자세하게 말하거나, 갑자기 다른 주제로 변경하는 모습을 보여 본 연구결과에 영향을 미쳤을 것으로 생각된다.

대화의 준언어적 측면에서, 고기능 자폐스펙트럼장애 집단과 일 반아동 집단은 말속도와 목소리 크기에서 유의한 차이가 없었으 나, 목소리 크기 변화, 목소리 높낮이(음도), 억양에서 집단 간 유의 한 차이가 나타났다. 이러한 결과는 전문가 집단이 고기능 자폐스 펙트럼장애 집단의 말속도와 목소리 크기는 일반아동과 크게 다르 지 않다고 지각하나, 목소리 크기 변화가 약간 부자연스러우며, 목 소리 높낮이(음도)는 약간 높거나 낮고, 억양은 약간 부자연스럽다 고 지각한다는 것을 나타내준다. 지각적 평가를 활용한 선행연구 들에서 자폐스펙트럼장애 아동과 청소년들은 일반 집단에 비해 비 전형적인 운율패턴을 보인다고 보고하였다(Bauminger-Zviely et al., 2014; Nadig \& Shaw, 2012; Paul et al., 2009; Seo, 2013). 전문가 집단이 아닌 부모를 대상으로 고기능 자폐스펙트럼장애 청소년의 준언어적 요인을 살펴본 Seo (2013)도 음성 크기, 속도, 리듬, 억양 등에서 문제를 보인다고 보고하였다. 따라서 자폐스펙트럼장애 집 단의 비전형적인 준언어적 특성은 아동기에서부터 지각될 수 있으 며, 일반 부모, 성인, 전문가 모두에게도 집단 간 차이를 지각할 수 있다고 해석할 수 있다.

대화의 비언어적 측면에서, 몸짓 빈도에서는 고기능 자폐스펙트 럼장애 집단과 일반아동 집단 간 유의한 차이를 보이지 않은 반면, 자세, 표정, 몸짓 적절성, 눈맞춤 빈도 및 적절성에서 두 집단 간 유 
의한 차이가 나타났다. 즉 전문가 집단은 고기능 자폐스펙트럼장 애 아동이 대화 시 사용하는 몸짓 빈도가 일반아동과 다르지 않다 고 지각하였으나, 사용하는 몸짓이 부적절하다고 지각하였다. 지각 적 평가를 통해 16-22세 고기능 자폐스펙트럼장애 청소년 및 성인 을 대상으로 몸짓 사용을 살펴본 Ratto, Turner-Brown, Rupp, Mesibov와 Penn (2011)도 몸짓 사용에서 일반아동과 유의한 차이를 보 이지 않는다고 보고하였으며, Bauminger-Zviely 등(2014)은 학령 전 고기능 자페스펙트럼장애 아동이 일반아동에 비해 부적절한 몸짓을 사용한다고 보고하였다. 즉, 전문가 집단은 고기능 자폐스 펙트럼장애 아동이 사용하는 몸짓의 빈도보다는 적절성 여부에 더 초점을 두고 지각한다고 해석할 수 있다. 전문가 집단은 자세, 눈 맞춤 빈도 및 적절성에서도 고기능 자폐스펙트럼장애 아동과 일반 아동이 다르다고 지각하였다. 대화에서의 지각적 평가를 통해 비언 어적 행동을 살펴본 선행연구들에서도 고기능 자폐스펙트럼장애 아동 및 청소년들은 일반아동에 비해 부적절한 시선/눈응시를 보 이는 것으로 보고되었다(Bauminger-Zviely et al., 2014; Paul et al., 2009; Seo, 2013). 즉 전문가 집단은 자폐스펙트럼장애 아동이 대화 중 대화 상대자를 향해 자세를 취하지 않고, 대화 상대자를 바라보 는 것이 적을 뿐만 아니라 부적절하다고 지각하였다. 대화 시 상대 방을 바라보거나 상대방을 향해 자세를 취하는 것은 상대방의 발 화에 관심을 갖고 집중하고 있다는 것을 반영해 주며 적극적으로 대화에 임한다는 것을 보여준다(Schwartz, Bente, Gawronnski, Schilbach, \& Vogeley, 2010). 전문자 집단은 고기능 자폐스펙트럼 장애 아동은 일반아동에 비해 상대방이 말하는 대화 내용에 관심 을 덜 갖고 소극적인 태도로 대화에 임하는 것으로 지각한다고 볼 수 있다.

마지막으로 단계적 판별분석을 실시하여 전문가 집단이 지각한 대화의 언어적, 준언어적, 비언어적 요인이 고기능 자폐스펙트럼장 애 집단과 일반아동 집단을 구별해 줄 수 있는지 확인하고, 두 집단 을 구별해 주는 데 가장 중요하게 기여해 주는 요인이 무엇인지 밝 히고자 하였다. 집단 간 차이를 보인 대화 요인을 대상으로 도출된 한 개의 판별함수는 통계적으로도 유의하였으며, 두 집단을 분류 하기 위해 사용한 대화 요인들은 집단 분류에 유용한 것으로 나타 났다. 고기능 자폐스펙트럼장애 집단과 일반아동 집단을 확인해 주는 최종 분류판별식을 사용하여 두 집단을 분류하였을 때, 고기 능 자폐스펙트럼장애를 고기능 자폐스펙트럼으로 확인해 주는 민 감도는 $76.4 \%$, 일반아동을 일반아동으로 확인해 주는 특이도는 $85.3 \%$ 로 나타났다. 본 연구결과의 민감도는 특이도에 비해 다소 낮 았으나 장애를 판별해 주는 중간 정도의 정확성을 보였다(Watkins, Kush, \& Schaefer, 2002). 이러한 결과를 토대로 본 연구에서
살펴본 대화 요인은 고기능 자폐스펙트럼장애 아동을 장애아동으 로 판별하고, 일반아동을 일반아동으로 판별하기에 적합한 것으 로 나타났다. 따라서 이러한 점을 고려하여 해석할 필요가 있을 것 이다.

고기능 자폐스펙트럼장애 집단과 일반아동 집단의 판별에 있어 서 중요하게 기여한 요인이 무엇인지 살펴본 결과, 주제변경 빈도, 주제유지 빈도 순으로 높은 중요도를 보였으며, 이 중 주제변경 빈 도가 두 집단을 판별해 주는 가장 중요한 요인으로 밝혀졌다. 지각 적 평가를 통해 대화 특성을 살펴본 선행연구들은 자폐스펙트럼장 애 아동이 일반아동에 비해 부적절하게 형식적인 주제로 이야기하 거나 주제에서 벗어난 이야기를 하는 등 언어적 측면에서 차이를 보고하였으며(Paul et al., 2009; Ratto et al., 2011 등), 음성 크기, 속 도, 억양 등 비전형적인 운율을 보이고(Nadig \& Shaw, 2012; Paul et al., 2009), 부적절한 시선, 몸짓, 표정에서도 일반아동과 유의한 차 이가 나타난다고 하였다(Ratto et al., 2011; Seo, 2013 등). 또한 본 연 구의 지각적 평가를 통해서도 고기능 자폐스펙트럼장애 아동은 언 어적 측면의 대화개시 적절성, 대화중첩, 주제유지와 변경의 빈도 및 적절성에서 일반아동과 차이를 보였으며, 준언어적인 측면에서 는 목소리 크기 변화, 목소리 높낮이, 억양에서, 언어적 측면에서는 눈맞춤 빈도 및 적절성, 자세, 표정, 몸짓의 빈도 및 적절성에서 유의 한 차이가 있는 것으로 나타났다. 이처럼 고기능 자폐스펙트럼장애 아동이 일반아동과 차이를 보이는 여러 대화 요인이 있었으나, 판 별분석을 통해 주제변경 빈도와 주제유지 빈도가 집단을 구별하는 데 두드러지게 설명해 주는 요인이라는 것을 밝혔다. 주제변경은 전 문가 집단에게 집단 간 다르다고 지각할 수 있으며, 대화 시 주제변 경을 많이 하는 특성은 자폐스펙트럼장애 집단을 구별해 주는 중 요한 요인이라고 해석할 수 있다. 고기능 자폐스펙트럼장애 아동은 대화 상대자에게 집중하지 않고 자신의 특정 관심사에 대해서만 이야기를 하거나(Tager-Flusberg et al., 2005) 손상된 마음이론으 로 인해(Peterson \& Siegal, 2000) 대화 상대자가 말한 주제와 관련 없이 다른 주제로 변경해버리는 비율이 높게 나타났을 가능성이 높다. 고기능 자폐스펙트럼장애 아동의 대화 평가 및 중재 시, 주제 변경에 초점을 두고 진행한다면 궁극적으로 대화 시 주제를 유지 하며 대화를 이어나가는 데에도 도움이 될 수 있을 것이다.

본 연구결과는 지각적 평가를 통해 고기능 자폐스펙트럼장애 아 동이 대화에서의 언어적, 준언어적, 비언어적 요인에서 어려움을 보 이는 것을 확인하였다. 또한 대화 요인 중 대화 주제변경과 대화 주 제유지가 고기능 자폐스펙트럼장애 아동을 판별해 주는 중요한 대 화 요인임을 밝혔다. 본 연구는 대화의 언어적, 준언어적, 비언어적 요인의 세 가지를 종합하여 파악하였다는 점에서 고기능 자폐스펙 
트럼장애 아동의 전반적인 대화 특성을 이해하는 데 중요한 정보는 제공해 주었다는 점에서 의의를 찾아볼 수 있다. 또한 고기능 자폐 스펙트럼장애 아동 집단을 구별해 줄 수 있는 대화적 요인을 밝힘 으로써 이후 대화 평가 및 중재에 중요한 정보를 제공할 수 있을 것 으로 생각된다.

\section{REFERENCES}

Adams, C., Lockton, E., Freed, J., Gaile, J., Earl, G., McBean, K., ... \& Law, J. (2012). The Social Communication Intervention Project: a randomized controlled trial of the effectiveness of speech and language therapy for school-age children who have pragmatic and social communication problems with or without autism spectrum disorder. International Journal of Language \& Communication Disorders, 47(3), 233-244.

Bauminger-Zviely, N., Karin, E., Kimhi, Y., \& Agam-Ben-Artzi, G. (2014). Spontaneous peer conversation in preschoolers with high-functioning autism spectrum disorder versus typical development. Journal of Child Psychology and Psychiatry, 55(4), 363-373.

Bishop, D. V. (2003). The Children's Communication Checklist: CCC-2. London: The Psychological Corporation.

Brinton, B., Fujiki, M., \& Powell, J. M. (1997). The ability of children with language impairment to manipulate topic in a structured task. Language, Speech, and Hearing Services in Schools, 28(1), 3-11.

Choi, J., \& Lee, Y. (2013). Conversational turn-taking and topic manipulation skills of children with high-functioning autism spectrum disorders. Communication Sciences \& Disorders, 18(1), 12-23.

Choi, J., \& Lee, Y. (2015). Contingency and informativeness of topic maintenance in children with high-functioning autism spectrum disorders. Communication Sciences \& Disorders, 20(3), 413-423.

Curcio, F., \& Paccia, J. (1987). Conversations with autistic children: contingent relationships between features of adult input and children's response adequacy. Journal of Autism and Developmental Disorders, 17(1), 81-93.

Evans, J. L., \& Craig, H. K. (1992). Language sample collection and analysis: interview compared to freeplay assessment contexts. Journal of Speech, Language, and Hearing Research, 35(2), 343-353.

Heo, H., \& Lee, Y. K. (2012). Conversational turn-taking and topic manipulation skills in conversations of school-age low-achievers in language learning. Korean Journal of Communication Disorders, 17(1), 66-78.

Hoff, E. (2009). Language development (5th ed.). Belmont, CA: Wadsworth Publishing.
Hong, U., \& Lee, Y. (2016). Conversational characteristics of children with a mild intellectual disability. Special Education Research, 15(2), 111-126.

Jo, S. S. (2002). A study on the discourse of children with autism spectrum disorders at the early stage of language development. Korean Journal of Communication Disorders, 7(3), 55-76.

Kim, Y. T., Hong, G. H., Kim, K. H., Jang, H. S., \& Lee, J. Y. (2009). Receptive \& expressive vocabulary test (REVT). Seoul: Seoul Community Rehabilitation Center.

Knapp, M. L., \& Hall, J. A. (2009). Nonverbal communication in human interaction (7th ed.). Belmont, CA: Wadsworth Publishing.

Lam, Y. G., \& Yeung, S. S. S. (2012). Towards a convergent account of pragmatic language deficits in children with high-functioning autism: depicting the phenotype using the Pragmatic Rating Scale. Research in Autism Spectrum Disorders, 6(2), 792-797.

Landa, R., Piven, J., Wzorek, M. M., Gayle, J. O., Chase, G. A., \& Folstein, S. E. (1992). Social language use in parents of autistic individuals. Psychological Medicine, 22(1), 245-254.

Lee, Y., \& Choi, J. (in press). Hallym Conversation and Pragmatic Assessment Protocol. Manuscript in preparation.

Lee, Y., Heo, H., \& Jang, S. (2015). Language Scale for School-aged Children (LSSC). Seoul: Hakjisa.

Lord, C., Rutter, M., DiLavore, P. C., Risi, S., Gotham, K., Bishop, S. L., ... \& Guthrie, W. (2012). ADOS-2: Autism Diagnostic Observation Schedule, second edition. Los Angeles, CA: Western Psychological Corporation.

Mehrabian, A. (1981). Silent messages: implicit communications of emotions and attitudes. Belmont, CA: Wadsworth Publishing.

Mentis, M. (1994). Topic management in discourse: assessment and intervention. Topics in Language Disorders, 14(3), 29-54.

Nadig, A., Lee, I., Singh, L., Bosshart, K., \& Ozonoff, S. (2010). How does the topic of conversation affect verbal exchange and eye gaze? A comparison between typical development and high-functioning autism. Neuropsychologia, 48(9), 2730-2739.

Nadig, A., \& Shaw, H. (2012). Acoustic and perceptual measurement of expressive prosody in high-functioning autism: increased pitch range and what it means to listeners. Journal of Autism and Developmental Disorders, 42(4), 499-511.

Nippold, M. A., Hesketh, L. J., Duthie, J. K., \& Mansfield, T. C. (2005). Conversational versus expository discourse. Journal of Speech, Language, and Hearing Research, 48(5), 1048-1064.

Nunnally, J. C. (1978). Psychometric theory (2nd ed.). New York, NY: McGraw- 
Hill.

Osberger, M. J. (1992). Scaling procedures for the measurement of speech intelligibility. In R. D. Kent (Ed.), Intelligibility in speech disorders (pp. 233263). Philadelphia, PA: John Benjamins Publishing.

Park, H. (2014). Korean version of Comprehensive Test of Nonverbal Intelligence second edition (K-CTONI-2). Seoul: Mindpress.

Park, Y. J., Choi, J., \& Lee, Y. (2017). Development of topic management skills in conversation of school-aged children. Communication Sciences \& Disorders, 22(1), 25-34.

Paul, R., Orlovski, S. M., Marcinko, H. C., \& Volkmar, F. (2009). Conversational behaviors in youth with high-functioning ASD and Asperger syndrome. Journal of Autism and Developmental Disorders, 39(1), 115-125.

Peterson, C. C., \& Siegal, M. (2000). Insights into theory of mind from deafness and autism. Mind \& Language, 15(1), 123-145.

Prutting, C. A., \& Kittchner, D. M. (1987). A clinical appraisal of the pragmatic aspects of language. Journal of Speech and Hearing Disorders, 52(2), 105-119.

Ratto, A. B., Turner-Brown, L., Rupp, B. M., Mesibov, G. B., \& Penn, D. L. (2011). Development of the contextual assessment of social skills (CASS): a role play measure of social skill for individuals with high-functioning autism. Journal of Autism and Developmental Disorders, 41(9), 1277-1286.

Schwartz, C., Bente, G., Gawronski, A., Schilbach, L., \& Vogeley, K. (2010). Responses to nonverbal behaviour of dynamic virtual characters in highfunctioning autism. Journal of Autism and Developmental Disorders, 40(1), 100-111.

Seo, G. H. (2013). Characteristics of nonverbal communication behaviors in adolescents with high functioning autism and Asperger disorder. Journal of Emotional \& Behavioral Disorders, 29(1), 73-106.
Tager-Flusberg, H., \& Anderson, M. (1991). The development of contingent discourse ability in autistic children. Journal of Child Psychology and Psychiatry, 32(7), 1123-1134.

Tager-Flusberg, H., Paul, R., \& Lord, C. (2005). Language and communication in autism. In F. R. Volkmar et al. (Eds.), Handbook of autism and pervasive developmental disorders (3rd ed., pp. 335-364). Hoboken, NJ: John Wiley \& Sons.

Tantam, D., Holmes, D., \& Cordess, C. (1993). Nonverbal expression in autism of Asperger type. Journal of Autism and Developmental Disorders, 23(1), 111-133.

Van Santen, J. P., Prud'Hommeaux, E. T., Black, L. M., \& Mitchell, M. (2010). Computational prosodic markers for autism. Autism, 14(3), 215-236.

Watkins, M. W., Kush, J. C., \& Schaefer, B. A. (2002). Diagnostic utility of the learning disability index. Journal of Learning Disabilities, 35(2), 98-103.

Wetherby, A. M. (1986). Ontogeny of communicative functions in autism. Journal of Autism and Developmental Disorders, 16(3), 295-316.

Yang, J., \& Choi, Y. (2010). The discourse characteristics of children with autism spectrum disorders: focused on turn-taking and the topic maintenance method. Korean Journal of Interdisciplinary Therapy, 2(1), 5-23.

Yang, Y., Lee, Y., Choi, J., \& Yoon, J. (2018). Development of conversational skills from late children to adolescent. Communication Sciences \& Disorders, 23(2), 270-278.

Yoo, H. J. (2008). Korean version of Social Communication Questionnaire. Seoul: Hakjisa.

Yoon, M., Lee, Y., \& Sim, H. S. (2000). The relationship between speech intelligibility and related factors of speakers in prelingually hearing impaired children using hearing aids. Korean Journal of Communication Disorders, 5(2), 144-158. 


\section{국문초록}

\section{학령기 고기능 자폐스펙트럼장애 아동을 판별하는 언어적, 비언어적 대화 요인: 지각적 평가를 중심으로 최지은 1 이윤경 \\ '한림대학교 대학원 언어병리청각학과, ${ }^{2}$ 한림대학교 언어청각학부}

배경 및 목적: 자폐스펙트럼장애 아동의 사회적 의사소통 결함은 다른 사람과의 대화를 어렵게 하며, 이는 또래와 적절한 사회적 관계 를 형성하는 데 어려움을 줄수 있고, 의사소통 상황에서 또래로부터 소외당하거나 사회적 문제들을 야기시킬 수 있다. 따라서 본 연구 는 지각적 평가를 통해 학령기 고기능 자폐스펙트럼장애 아동의 대화 능력을 언어적, 준언어적, 비언어적 특성으로 살펴보고 이 중 집 단을 판별해 주는 요인이 무엇인지 확인하고자 하였다. 방법: 학령기 고기능 자폐스펙트럼장애 아동 17 명과 일반아동(생활연령일치 17 명, 언어연령일치 17 명) 34 명을 대상으로 하였다. 51 명의 대화 자료는 무선적으로 배치하여 언어재활사 전문가 6 명에게 제시한 후, 지각 적 평정 척도를 활용하여 언어적, 준언어적, 비언어적 측면에 대해 평가하도록 하였다. 결과: 언어적 측면에서 고기능 자폐스펙트럼장애 아동은 대화개시 부적절, 대화중첩, 주제유지 및 변경 빈도, 주제유지 및 변경 부적절에서 유의하게 높은 점수를 받았다. 준언어적 측면 에서는 목소리 크기변화, 목소리 높낮이 억양에서 유의하게 높은 점수를 받았으며, 비언어적 측면에서는 자세, 표정, 몸짓 부적절, 눈맞 춤 빈도 및 부적절 점수에서 유의하게 높았다. 판별분석 결과, 주제변경 빈도, 주제유지 빈도 순으로 고기능 자폐스펙트럼장애 집단을 판별하는 데 가장 중요한 대화 요인인 것으로 나타났다. 논의 및 결론: 연구결과에 따라 고기능 자폐스펙트럼장애 집단의 대화 특성과 집단을 판별해 주는 대화 요인에 대하여 논의하였다.

핵심어: 지각적 평가, 고기능 자폐스펙트럼장애, 언어적, 비언어적, 대화 요인

본 논문은 제1저자의 박사학위논문(2019)의 일부를 발췌한 것임.

\section{참고문헌}

김영태, 홍경훈, 김경희, 장혜성, 이주연(2009). 수용·표현어휘력검사(REVT). 서울: 서울장애인종합복지관.

박윤정, 최지은, 이윤경(2017). 초등학생 아동의 대화주제관리 능력의 발달. Communication Sciences \& Disorders, 22(1), 25-34.

박혜원(2014). 한국 비언어지능검사 2판(K-CTONI-2). 서울: 마인드프레스.

서경희(2013). 고기능 자폐장애 청소년과 아스퍼거장애 청소년의 비언어적 의사소통 특성. 정서 · 행동장애연구, 29(1), 73-106.

양예원, 이윤경, 최지은, 윤지혜(2018). 후기 아동기에서 청소년기까지의 대화발달. Communication Sciences \& Disorders, 23(2), 270-278.

양정연, 최예린(2010). 자폐스펙트럼장애 청소년의 대화방법 특성. 통합치료연구, 2(1), 5-23.

유희정(2008). 한국판 사회적 의사소통 설문지(SCQ). 서울: 학지사

윤미선, 이윤경, 심현섭(2000). 청각장애아동의 말명료도에 영향을 미치는 화자요인. 언어청각장애연구, 5(2), 144-158.

이윤경, 허현숙, 장승민(2015). 학령기 아동 언어검사(LCCS). 서울: 학지사.

조성숙(2002). 언어발달 초기단계에 있는 자폐성 장애아동의 대화방법에 관한 연구: 차례지키기와 주제유지방법을 중심으로. 언어청각장애연구,

7(3), 55-76.

최지은, 이윤경(2013). 학령기 고기능 자폐범주성장애 아동의 대화차례 주고받기 및 주제운용능력. Communication Sciences \& Disorders, 18(1), 12-23.

최지은, 이윤경(2015). 학령기 고기능 자폐스펙트럼장애 아동의 주제유지능력. Communication Sciences \& Disorders, 20(3), 413-423.

허현숙, 이윤경(2012). 언어학습부진아동의 대화차례 주고받기 및 주제운용특성. 언어청각장애연구, 17(1), 66-78.

홍욱표, 이윤경(2016). 경도지적장애아동의 대화특성. 특수교육, 15(2), 111-126.

\section{ORCID}

최지은(https://orcid.org/0000-0002-4141-4096); 이윤경(https://orcid.org/0000-0002-9759-6247) 